\title{
Avaliação do acesso ao serviço prestado pela Atenção Primária de Saúde na Região de Saúde Sudoeste I do Estado de Goiás
}

\author{
Evaluation of access to the service provided by Primary Health Care in the Southwest Health \\ Region I of the State of Goiás \\ Evaluación del acceso al servicio de Atención Primaria de Salud en la Región Sudoeste I de Salud \\ del Estado de Goiás
}

Recebido: 21/03/2021 | Revisado: 28/03/2021 | Aceito: 31/03/2021 | Publicado: 10/04/2021
Isabella Aparecida Vasconcelos Moreira ORCID: https://orcid.org/0000-0001-6172-561X
Universidade de Rio Verde, Brasil
E-mail: isabellaavm133@gmail.com
Adriele Viana Resende
ORCID: https://orcid.org/0000-0001-8372-8192
Universidade de Rio Verde, Brasil
E-mail: adrieleviana.enfermeira@gmail.com
Ludmila Grego Maia
ORCID: https://orcid.org/0000-0002-7771-8040
Universidade Federal de Goiás, Brasil E-mail: ludmila@ufg.br
Marcelo Gomes Judice
ORCID: https://orcid.org/0000-0001-8836-0059 Universidade de Rio Verde, Brasil
E-mail: mgjudice@unirv.edu.br
Agatha Victória Sousa Mota
ORCID: https://orcid.org/0000-0003-0066-8089 Universidade de Rio Verde, Brasil
E-mail: agathavictoria1998@gmail.com
Camila Martins Ribeiro
ORCID: https://orcid.org/0000-0001-5148-9051 Universidade de Rio Verde, Brasil E-mail: camilamribeiro15@gmail.com
Carolina Ramos Pasieka
ORCID: https://orcid.org/0000-0002-9690-2257
Universidade de Rio Verde, Brasil
E-mail: carolina.pasiekacr47@gmail.com
Jéssica Renata Mariana da Silva
ORCID: https://orcid.org/0000-0003-3928-7902
Universidade de Rio Verde, Brasil
E-mail: jessicarenata.mariana@gmail.com

\begin{abstract}
Resumo
A efetivação dos princípios do Sistema Único de Saúde é um grande desafio para a Atenção Primária de Saúde, porque depende da presença dos atributos de saúde. O acesso refere-se à utilização dos serviços de saúde pelo usuário, e quando ausente pode acarretar no baixo desempenho do Sistema e supostamente aumentar a taxa de Internações por Condições Sensíveis à Atenção Primária. Objetivo: Avaliar as condições do acesso ao serviço prestado pela Atenção Primária de Saúde na Região de Saúde Sudoeste I. Materiais e Métodos: Estudo transversal com abordagem quantitativa, realizado por meio de dados secundários referentes às Internações por Condições Sensíveis à Atenção Primária extraídos do Sistema de Informações Hospitalares e aplicação do instrumento PCATool - Brasil para pacientes internados em leitos públicos. Utilizado o Microsoft Excel para refinamento dos dados e um programa estatístico para análise descritiva. Resultados: Ocorreram 19.993 Internações por Condições Sensíveis no município de Rio Verde no período de 2010 a 2019. Prevaleceram os diagnósticos de insuficiência cardíaca, pneumonias bacterianas, gastroenterites infecciosas e complicações, infecção no rim e trato urinário e doenças pulmonares. Dos 260 entrevistados entre abril/2019 e março/2020, 51,92\% referem-se a adultos e 48,07\% a crianças; $77 \%$ não possuíam nenhum grau de afiliação à APS. Conclusão: O acesso ao serviço prestado pela APS da região estudada se encontra insatisfatório, sendo necessário a reformulação das políticas públicas, programas e ações de saúde que estão sendo desenvolvidos a fim de aumentar a cobertura na região.
\end{abstract}


Palavras-chave: Acesso aos serviços de saúde; Sistema Único de Saúde; Avaliação em Saúde; Atenção primária de saúde.

\begin{abstract}
The implementation of the principles of the Unified Health System is a major challenge for Primary Health Care, because it depends on the presence of health attributes. Access refers to the use of health services by the user, and when absent it can result in the low performance of the System and supposedly increase the rate of Hospitalizations for Conditions Sensitive to Primary Care. Objective: To evaluate the conditions of access to the service provided by Primary Health Care in the Southwest Health Region I. Materials and Methods: Cross-sectional study with a quantitative approach, carried out using secondary data referring to Hospitalizations for Conditions Sensitive to Primary Care extracted from the System of Hospital Information and application of the PCATool - Brazil instrument for patients hospitalized in public beds. Microsoft Excel was used for data refinement and a statistical program for descriptive analysis. Results: There were 19,993 Hospitalizations for Sensitive Conditions in the municipality of Rio Verde in the period from 2010 to 2019. The diagnoses of heart failure, bacterial pneumonia, infectious gastroenteritis and complications, kidney and urinary tract infection and lung diseases prevailed. Of the 260 respondents between April / 2019 and March / 2020, 51.92\% refer to adults and 48.07\% to children; 77\% did not have any degree of PHC affiliation. Conclusion: Access to the service provided by PHC in the studied region is unsatisfactory, requiring the reformulation of public policies, programs and health actions that are being developed in order to increase coverage in the region.
\end{abstract}

Keywords: Access to health services; Unified Health System; Health assessment; Primary health care.

\title{
Resumen
}

La implementación de los principios del Sistema Único de Salud es un gran desafío para la Atención Primaria de Salud, porque depende de la presencia de atributos de salud. El acceso se refiere al uso de los servicios de salud por parte del usuario, y en su ausencia puede resultar en el bajo rendimiento del Sistema y supuestamente aumentar la tasa de Hospitalizaciones por Condiciones Sensibles a Atención Primaria. Objetivo: Evaluar las condiciones de acceso al servicio brindado por la Atención Primaria de Salud en la Región Sanitaria Suroeste I. Materiales y Métodos: Estudio transversal con abordaje cuantitativo, realizado con datos secundarios referidos a Hospitalizaciones por Condiciones Sensibles a la Atención Primaria. extraído del Sistema de Información Hospitalaria y aplicación del instrumento PCATool - Brasil para pacientes hospitalizados en camas públicas. Se utilizó Microsoft Excel para el refinamiento de los datos y un programa estadístico para el análisis descriptivo. Resultados: Se registraron 19.993 Hospitalizaciones por Condiciones Sensibles en el municipio de Río Verde en el período de 2010 a 2019. Prevalecieron los diagnósticos de insuficiencia cardíaca, neumonía bacteriana, gastroenteritis infecciosa y complicaciones, infección renal y del tracto urinario y enfermedades pulmonares. De los 260 encuestados entre abril / 2019 y marzo / 2020, el 51,92\% se refiere a adultos y el 48,07\% a niños; El 77\% no tenía ningún grado de afiliación a la APS. Conclusión: El acceso al servicio brindado por la APS en la región de estudio es insatisfactorio, requiriendo la reformulación de políticas públicas, programas y acciones de salud que se están desarrollando para incrementar la cobertura en la región.

Palabras clave: Acceso a los servicios de salud; Sistema de Salud Unificado; Evaluación de la salud; Primeros auxilios.

\section{Introdução}

Atenção Primária à Saúde (APS) é o primeiro nível de atenção à saúde, sendo considerada a porta de entrada do Sistema Único de Saúde (SUS) e o primeiro contato dos usuários com o sistema. A Atenção Básica (AB) apresenta procedimentos que demandam de baixa tecnologia e baixo custo como serviços de prevenção, promoção, diagnóstico precoce, tratamento, cuidados paliativos e vigilância, disponíveis em unidades de saúde próximas as residências dos indivíduos, com o objetivo de atender a maior parte da demanda de saúde-doença da da população de um território predefinido. As ações ocorrem por meio de uma equipe multidisciplinar que visa sanar as necessidades de saúde tanto em âmbito individual quanto coletivo, além de melhorar o acesso (Brasil, 2017; Brasil, 2003; Brasil, 2007). A APS apresenta 4 atributos essenciais: a atenção ao primeiro contato, a longitudinalidade, a integralidade e a coordenação. Além dos atributos essenciais existem os atributos derivados que consistem em: orientação familiar, orientação coletiva e a competência cultural (Starfield, 2002; Silva, Nogueira, Paraizo, \& Fracolli, 2014).

A Estratégia de Saúde da Família (ESF) é composta pelos seguintes programas e ações: Saúde na Hora, Política Nacional do Idoso, Política Nacional de Atenção Integral à Saúde do Homem, Programa de Assistência Integral à Saúde da Mulher, Política de Atenção Integral à Saúde da Criança, Programa Academia da Saúde, Programa Nacional de Imunização, 
entre outros. Porém, para além da diversidade de programas, para que haja adesão da população a eles, é essencial que a AB atue com atendimentos humanizados, rápidos e resolutivos, além de se mostrar acolhedora e de fácil acesso para sua comunidade (Brasil, 2019; Campos et al., 2014; Campos, 2015). A ESF que surgiu por meio da Política Nacional de Atenção Básica (PNAB), é uma importante estratégia de consolidação, qualificação e ampliação da AB no país, pois, ela mantém o vínculo com o paciente e sua família, sendo um instrumento essencial para alcançar a universalidade, equidade e integralidade nos serviços (Brasil, 2017; Oliveira \& Pereira, 2013).

Neste estudo, adotou-se como acesso a utilização dos serviços de saúde pelos cidadãos. Para que o acesso ser efetivo é necessário que haja acolhimento de todas as pessoas no território de referência de modo universal e sem discriminação ou exclusão. Entretanto, os maiores limites e desafios da $\mathrm{AB}$ estão relacionados ao acolhimento e ao vínculo, e para serem resolvidos, é necessário que a justiça social esteja presente, haja uma democracia concreta, o número dos indivíduos que defendam a saúde como direito fundamental aumente, ocorra um aprimoramento da participação e controle social, a universalização da cobertura, a resolutividade, a valorização dos profissionais de saúde, a reforma do Estado, entre outros. As desigualdades sociais presentes no país serão sanadas somente quando a população lutar pelos seus direitos e pela democracia, como por exemplo, a participação social (Barbiani, Junges, Nora, \& Asquidamini, 2014; Gadelha, 2015; Lima et al., 2015; Santos \& Silva, 2013; Souza et al., 2019).

A efetivação dos princípios do SUS na APS é um desafio. O acesso aos serviços de saúde engloba os aspectos socioeconômicos, demográficos, políticos, técnicos e organizacionais. Ou seja, a busca do usuário pelo atendimento de saúde na APS, dependerá de seu nível de escolaridade, renda, transporte, localização da residência, se existe uma ESF no seu território, se os serviços de saúde estão disponíveis, se houve corte ou desvio de verbas da unidade, o reflexo da gestão política na $\mathrm{AB}$, entre outros. Perante esse cenário, pode-se dizer que os fatores citados podem acarretar no baixo desempenho do Sistema, afetando a qualidade de vida dos pacientes e também aumentando a taxa de Internações por Condições Sensíveis à Atenção Primária - ICSAP.

As ICSAP consistem em um indicador epidemiológico que identifica as internações evitáveis de acordo com a efetividade e acessibilidade da $\mathrm{AB}$. Estudos indicam que a expansão da ESF está associada com a tendência de redução das ICSAP. A fim de diminuir as ICSAP é preciso investir na qualidade da ESF e na reorganização do seu processo de trabalho (Carriello, Souza, \& Vallegas, 2020). Para categorização deste tipo de internação, existe uma lista com 19 grupos de causas de diagnósticos publicada por meio da Portaria 221/2008 do Ministério da Saúde. Portanto, ressalta-se que as ICSAP devem ser evitadas pela rede de $\mathrm{AB}$, desde que a mesma conte com condições para realização de assistência adequada.

Sendo a $\mathrm{AB}$ um serviço essencial, é importante que seja avaliada pelos próprios usuários, para que assim, os gestores possam identificar falhas, e traçar possíveis soluções, acarretando melhoras tanto para a assistência de saúde quanto para os pacientes. Desse modo, o estudo avaliou as condições do acesso aos serviços prestados pela APS da Região de Saúde Sudoeste I no estado de Goiás, Brasil.

Neste caso, a $\mathrm{AB}$ se mostra como um serviço essencial, que precisa ser avaliado pelos próprios usuários, para que, assim, os gestores possam identificar falhas e traçar possíveis soluções, o que acarreta em melhorias tanto para a assistência de saúde quanto para os pacientes.

\section{Materiais e Métodos}

Estudo epidemiológico, exploratório, analítico, descritivo, transversal, com abordagem quantitativa, que busca informações acerca da qualidade do acesso de adultos, crianças, adolescentes e/ou responsáveis aos serviços de saúde de AP, localizados na Região de Saúde Sudoeste I, do Estado de Goiás, no Centro-Oeste do Brasil, no período de abril/2019 a março/2020. 
O estudo evidenciou as causas mais prevalentes de internações por condições sensíveis à Atenção Primária na Região, mensurou os aspectos de estrutura, processo e resultados dos serviços de saúde da Atenção Básica e investigou a qualidade do acesso aos serviços prestados pela Atenção Primária aos usuários da Região de Saúde Sudoeste I do Estado de Goiás.

Em Goiás, o estado é dividido em 18 regiões de saúde e 5 macrorregiões que têm sedes administrativas nomeadas de Regionais de Saúde, estas últimas retratam a Secretaria de Estado de Saúde (SES). A Região Sudoeste I é composta por 18 municípios, sendo Rio Verde o que possui maior quantidade de habitantes (cerca de 235.600), estabelecendo-se como sede desta Regional de Saúde. Em 2019, esta região possuía 89 equipes de ESF cadastradas e a cobertura da AB alcança 58,53\% da população (Brasil, 2017; Instituto Brasileiro de Geografia e Estatística, 2019; Prefeitura de Rio Verde, 2019).

Acerca da cobertura da ESF e da AB no país, em 2015, o percentual era 61,5\% e 73\%, respectivamente. Após 5 anos, especificamente em abril $/ 2020$, estes valores foram $65 \%$ e $76 \%$, relativamente. Ambos elevaram-se gradualmente, a cada ano. Em relação ao estado de Goiás, em 2015, a cobertura média da ESF e da AB era 65\% e 72\%. Já em 2020, a abrangência foi $68 \%$ e $74 \%$, na ordem respectiva. Nota-se que estes percentuais oscilaram no decorrer dos 5 anos analisados. No que concerne à Região de Saúde Sudoeste I, a média da cobertura da ESF e AB nos municípios em 2015 foi 55,4\% e 63,5\%, enquanto no ano de 2020 apresentou 55\% e 68\% (Brasil, 2017).

Rio Verde-GO, o maior município desta região, possuía a cobertura de cerca de $15 \%$ (ESF) e $32 \%$ (AB) no ano de 2015, entretanto, em abril de 2020 apresentou $22 \%$ e 41\%, respectivamente. Houve um ligeiro aumento, porém, este município juntamente com Itarumã (96\%), Maurilândia (98\%), Porteirão (89\%), Quirinópolis (89\%) e São Simão (83\%), são os únicos que não obtiveram 100\% da cobertura na Região de Saúde Sudoeste I (Brasil, 2017). Entre todos estes municípios do Estado, Rio Verde tem a cobertura mais baixa, o que pode influenciar no aumento de ICSAP.

A aplicação de questionários foi realizada em hospitais vinculados ao SUS da região e foram incluídos na amostra os indivíduos que possuíam o Código Internacional de Doenças -CID de Condições Sensíveis na Autorização de Internação Hospitalar - AIH, aqueles que estavam conscientes ou que possuíam um acompanhante para responder o questionário. Foram excluídos os pacientes que não residiam nos municípios cobertos pela Regional de Saúde Sudoeste I e/ou estavam hospitalizados na Unidade de Terapia Intensiva - UTI. Além destes, foram excluídos da pesquisa um total de 36 usuários. Sendo que 22 não apresentavam o CID na AIH, 10 que se recusaram a participar e 4 que não possuíam acompanhante, estavam em precaução de contato ou receberam alta. O número da amostra foi de 260 participantes, sendo definida por meio de cálculo para validade estatística do número das internações, com base nas variáveis consideradas dos últimos 3 anos. Para garantir a confiabilidade da amostra, define-se como amostra de situação devido à impossibilidade de continuidade da coleta em função da pandemia do novo Coronavírus.

Previamente ao início da coleta de dados, as pesquisadoras foram treinadas de acordo com o proposto pelo manual PCATool-Brasil e efetuaram a transcrição das versões adulto e criança do instrumento para uma plataforma online do Google Drive, o Google Forms. Os formulários eram acessados por meio de tablets com acesso à internet. Isto foi realizado a fim de poupar tempo, facilitar as entrevistas e análises posteriores, pois a plataforma disponibiliza os dados em gráficos ou planilhas do Microsoft Excel.

Em relação às entrevistas, primeiramente as pesquisadoras identificaram o CID na AIH dos pacientes, logo após se dirigiam aos quartos para abordar os indivíduos a beira leito. O Termo de Consentimento Livre e Esclarecido (TCLE) era apresentado, as dúvidas eram sanadas e diante do aceite o questionário era aplicado. A duração média das entrevistas foi de 20 a 30 minutos.

O PCATool foi validado no Brasil e avalia a estrutura, os processos e resultados da APS. A versão adulto possui 87 itens divididos em 10 componentes associados aos atributos da $\mathrm{AB}$; e a versão criança possui 55 itens divididos em 10 componentes. As seções examinam cada um dos seguintes atributos da AB: acesso de primeiro contato, acessibilidade, 
utilização, longitudinalidade, coordenação, integração dos cuidados, sistema de informação, integralidade, serviços prestados e serviços disponíveis (Brasil, 2010).

Esses atributos foram analisados por meio de questões que possuem como respostas possíveis os seguintes elementos da escala tipo Likert: "com certeza sim" (valor =4), "provavelmente sim" (valor = 3), "provavelmente não" (valor = 2), "com certeza não" (valor =1) e "não sei/não lembro" (valor = 9). No caso da versão-criança, o resultado de cada atributo e seus componentes é calculado pela média dos valores das respostas dos itens que os compõem. Enquanto isto, na versão adulto os escores são calculados por meio da aritmética simples. Após, os escores de cada atributo são transformados numa escala de 0 a 10, através da fórmula a seguir (Brasil, 2010):

(escore obtido - 1) x 10

Os dados do Google Forms foram baixados através de gráficos e planilhas do Microsoft Excel. Para cada item avaliado foi criado uma tabela e um gráfico, a fim de facilitar a análise. Foi realizada a análise descritiva dos dados. Os dados secundários referentes às ICSAP foram retirados do Sistema de Informações Hospitalares do Sistema Único de Saúde (SIH/SUS). Aplicou-se o software Tab para Windows - TabWin versão 3.6b - para extração dos dados, programa disponibilizado pelo Ministério da Saúde, sendo analisadas as hospitalizações por ICSAP dos últimos 10 anos na região de estudo.

Essa pesquisa é uma extensão do projeto original "Observatório das internações por condições sensíveis à Atenção Primária à Saúde: possibilidades de melhoria do acesso e resolutividade", cujo projeto foi aprovado pelo parecer $\mathrm{n}^{\circ} 3.123 .689$ do Comitê de Ética em Pesquisa (CEP) da Universidade Federal de Goiás - UFG através da Plataforma Brasil. Seguindo a Resolução no 466 de 12 de dezembro de 2012, imposta pelo Conselho Nacional de Saúde.

\section{Resultados}

De acordo com os dados coletados no Tabwin e no DataSUS, no período de 2010 a 2019, ocorreram 19.993 internações por condições sensíveis à Atenção Primária no município de Rio Verde. As cinco principais causas de hospitalizações identificadas foram: insuficiência cardíaca com 11,89\% (2378), pneumonias bacterianas com 11,79\% (2359), gastroenterites infecciosas e complicações com 11,56\% (2313), infecção no rim e trato urinário com 11,26\% (2252) e doenças pulmonares com 10,84\% (2168). Todas as ICSAP estão disponíveis na Tabela 1. 
Tabela 1. Movimento de Autorização de Internação Hospitalar de Internações por Condições Sensíveis à Atenção Primária em Rio Verde-GO, Brasil, no período de 2010 a 2019.

\begin{tabular}{|c|c|c|}
\hline $\begin{array}{c}\text { Condições Sensíveis em ordem } \\
\text { decrescente }\end{array}$ & $\mathbf{N}^{\circ}$ de internações & $\%$ \\
\hline Insuficiência cardíaca & 2378 & $11,89 \%$ \\
\hline Pneumonias bacterianas & 2359 & $11,79 \%$ \\
\hline Gastroenterites Infecciosas e complicações & 2313 & $11,56 \%$ \\
\hline Infecção no rim e trato urinário & 2252 & $11,26 \%$ \\
\hline Doenças pulmonares & 2168 & $10,84 \%$ \\
\hline Angina & 1307 & $6,53 \%$ \\
\hline Doenças cerebrovasculares & 1220 & $6,10 \%$ \\
\hline Infecções de ouvido, nariz e garganta & 1143 & $5,71 \%$ \\
\hline Infecção da pele e tecido subcutâneo & 1051 & $5,25 \%$ \\
\hline Doenças relacionadas ao pré-natal e parto & 1011 & $5,05 \%$ \\
\hline Diabetes melitus & 861 & $4,30 \%$ \\
\hline Asma & 448 & $2,24 \%$ \\
\hline Úlcera gastrointestinal & 402 & $2,01 \%$ \\
\hline Epilepsias & 368 & $1,84 \%$ \\
\hline Deficiências nutricionais & 340 & $1,70 \%$ \\
\hline Hipertensão & 132 & $0,66 \%$ \\
\hline $\begin{array}{l}\text { Doença Inflamatória órgãos pélvicos } \\
\text { femininos }\end{array}$ & 125 & $0,62 \%$ \\
\hline $\begin{array}{l}\text { Doenças preveníveis p/imuniz/condições } \\
\text { sensív }\end{array}$ & 100 & $0,50 \%$ \\
\hline Anemia & 15 & $0,07 \%$ \\
\hline Total & 19993 & $100 \%$ \\
\hline
\end{tabular}

Fonte: Tabwin - DataSUS, Região de Saúde Sudoeste I (2020).

Em alguns anos, essas cinco causas principais divergem. Nos anos de 2010 e 2011, o grupo de doenças vasculares esteve presente. Já nos anos de 2012, 2015 e 2016, encontra-se o grupo de infecção de ouvido, nariz e garganta. Em contrapartida, o ano de 2014 apresenta o grupo de infecção da pele e tecido subcutâneo. Nos últimos 3 anos, foi identificado o grupo de doenças relacionadas ao pré-parto e parto. Os anos de 2017 e 2019 exibem as doenças cerebrovasculares. Enquanto, nos últimos 2 anos, o grupo angina se mostra presente.

No Gráfico 1, nota-se que o número total de ICSAP se manteve elevado nos anos de 2010 a 2015, tendo uma média de 2.150 internações. Em contrapartida, no ano de 2016 este valor diminuiu e, em 2017, atingiu a menor quantidade dos últimos 10 anos, que foram 1.529 internações. Nos anos posteriores, esse número voltou a subir, atingindo em 2019 a marca de 1852 ICSAP. 
Gráfico 1. Número total de Internações por Condições Sensíveis a Atenção Primária na Região de Saúde Sudoeste I, GoiásBrasil, de 2010 a 2019.

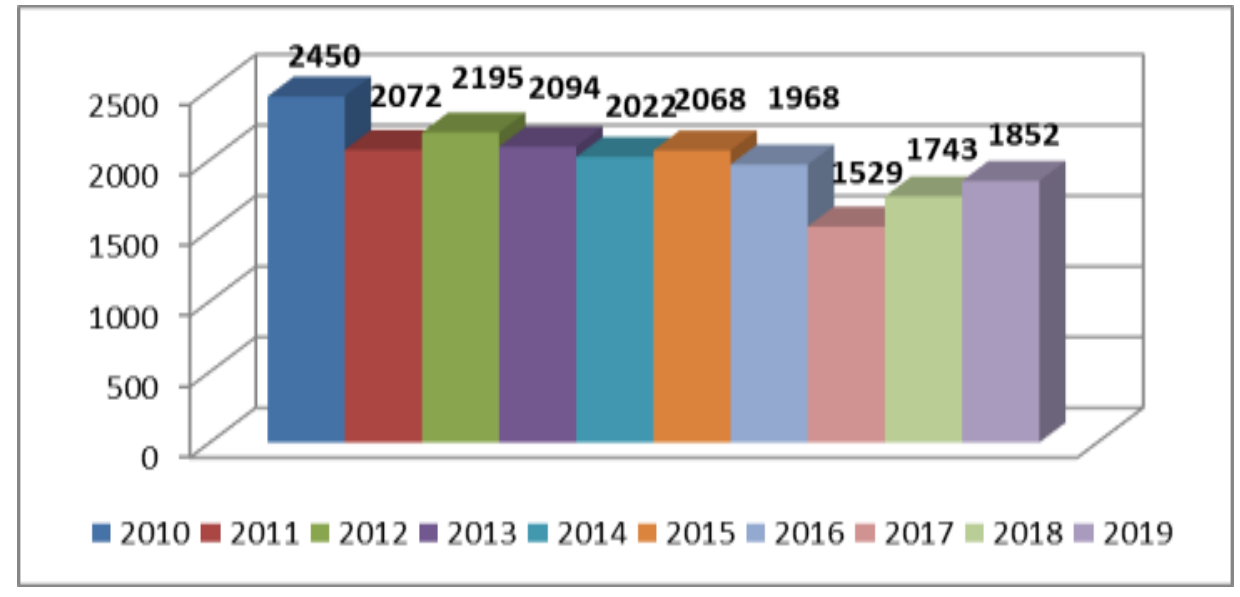

Fonte: Tabwin - DataSUS, Região de Saúde Sudoeste I (2020).

Durante o período de 24 de abril de 2019 a 14 de março de 2020, foram entrevistados 260 pacientes e responsáveis por crianças, sendo que 136 (52\%) responderam ao PCATool - Versão Adulto e 124 (48\%) ao PCATool - Versão Criança.

O item A do instrumento refere-se ao grau de afiliação com um serviço e/ou profissional de saúde. Neste item, cerca de $77 \%(n=200)$ dos entrevistados negam possuir este vínculo, enquanto $23 \%(n=60)$ afirmaram possuir. Em relação à cobertura da ESF no bairro de residência, $44 \%$ alegaram possuir, enquanto $42 \%$ negaram e $14 \%$ não sabem. As informações estão dispostas no Gráfico 2.

Gráfico 2. Percentual de afiliação dos pacientes entrevistados aos serviços da Atenção Primária de Saúde e Cobertura da Estratégia de Saúde da Família no bairro de residência, no município de Rio Verde-GO, Brasil, no período de 2019-2020.

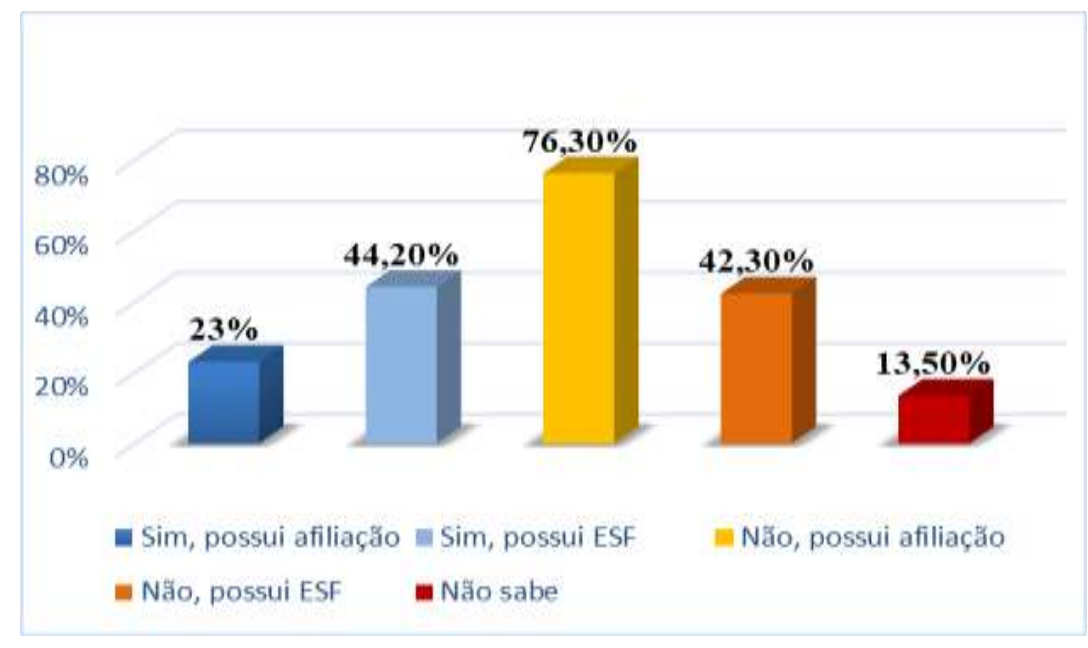

Fonte: Primary Care Assessment Tool, Região de Saúde Sudoeste I (2020).

Na Tabela 2 (abaixo) estão as médias gerais dos itens B, C, D, F, G, H, I e J do questionário. O componente B avalia o acesso de primeiro contato e objetiva identificar a utilização dos serviços de saúde ou da assistência de um profissional. 43\% ( $\mathrm{n}=112)$ responderam que não sabem/não lembram se buscam os serviços da APS, seguidos por 32,33\% ( $\mathrm{n}=83$ ) que alegaram que com certeza não buscam, $17,33 \%(n=44)$ que buscam com certeza os serviços, $6 \%(n=16)$ que provavelmente buscam e $2 \%(\mathrm{n}=5)$ que provavelmente buscam os serviços da APS. 
Tabela 2. Percentual dos itens B, C, D, F, G, H, I e J do instrumento Primary Care Assessment Tool, em Rio Verde-GO, Brasil, no período de 2019-2020.

\begin{tabular}{|c|c|c|c|c|c|c|c|c|c|c|}
\hline \multirow[t]{2}{*}{ Itens } & \multicolumn{2}{|c|}{$\begin{array}{c}\text { Não sei/Não } \\
\text { lembro }\end{array}$} & \multicolumn{2}{|c|}{$\begin{array}{c}\text { Com certeza, } \\
\text { não }\end{array}$} & \multicolumn{2}{|c|}{$\begin{array}{c}\text { Com certeza, } \\
\text { sim }\end{array}$} & \multicolumn{2}{|c|}{$\begin{array}{l}\text { Provavelmente, } \\
\text { sim }\end{array}$} & \multicolumn{2}{|c|}{$\begin{array}{c}\text { Provavelmente, } \\
\text { não }\end{array}$} \\
\hline & $\mathbf{n}$ & $\%$ & $\mathbf{n}$ & $\%$ & $\mathbf{n}$ & $\%$ & $\mathbf{n}$ & $\%$ & $\mathbf{n}$ & $\%$ \\
\hline $\begin{array}{l}\text { B. Acesso de primeiro } \\
\text { contato (utilização) }\end{array}$ & 112 & $43 \%$ & 83 & $32 \%$ & 44 & $17 \%$ & 16 & $6 \%$ & 5 & $2 \%$ \\
\hline $\begin{array}{l}\text { C. Acesso de primeiro } \\
\text { contato (acessibilidade) }\end{array}$ & 122 & $47 \%$ & 104 & $40 \%$ & 21 & $8 \%$ & 8 & $3 \%$ & 5 & $2 \%$ \\
\hline D. Longitudinalidade & 120 & $46 \%$ & 91 & $35 \%$ & 31 & $12 \%$ & 10 & $4 \%$ & 8 & $3 \%$ \\
\hline $\begin{array}{l}\text { F. Coordenação (sistema } \\
\text { de informações) }\end{array}$ & 125 & $48 \%$ & 83 & $32 \%$ & 36 & $14 \%$ & 13 & $5 \%$ & 3 & $1 \%$ \\
\hline $\begin{array}{l}\text { G. Integralidade (serviços } \\
\text { disponíveis) }\end{array}$ & 146 & $56 \%$ & 86 & $33 \%$ & 21 & $8 \%$ & 5 & $2 \%$ & 2 & $1 \%$ \\
\hline $\begin{array}{l}\text { H. Integralidade (serviços } \\
\text { prestados) }\end{array}$ & 135 & $52 \%$ & 94 & $36 \%$ & 21 & $8 \%$ & 5 & $2 \%$ & 5 & $2 \%$ \\
\hline I. Orientação familiar & 133 & $51 \%$ & 91 & $35 \%$ & 21 & $8 \%$ & 10 & $4 \%$ & 5 & $2 \%$ \\
\hline J. Orientação comunitária & 130 & $50 \%$ & 104 & $40 \%$ & 18 & $7 \%$ & 5 & $2 \%$ & 3 & $1 \%$ \\
\hline
\end{tabular}

Fonte: Primary Care Assessment Tool, Região de Saúde Sudoeste I (2020).

No item $\mathrm{C}$ que avalia o acesso de primeiro contato no âmbito de acessibilidade, $47 \%(\mathrm{n}=122)$ relataram não saberem ou não lembrarem e $40 \%(\mathrm{n}=104)$ afirmaram que com certeza não têm tal acessibilidade, $8 \%$ (n=21) afirmaram possuir com certeza a acessibilidade, $3 \%(n=8)$ alegam que provavaelmente não possuem e $2 \%(n=5)$ que não possuem.

Já o componente D averigua a longitudinalidade, 45,5\% $(\mathrm{n}=120)$ dizem não saber/não lembrar e 34,5\% (n=91) com certeza não têm, $12 \%(n=31)$ afirmaram possuir com certeza, 4\% $(n=10)$ alegam que provavelmente possuem enquanto $3 \%$ $(\mathrm{n}=8)$ provavelmente não possuem.

O tópico E analisa a coordenação (integração de cuidados), onde $60 \%(\mathrm{n}=75)$ dos entrevistados não possuem, $31 \%$ $(n=38)$ relataram não saber/não lembrar e apenas $9 \%(n=11)$ afirmaram que possuem.

O item F avalia a coordenação acerca dos sistemas de informações, dos pacientes avaliados, onde 47,6\% (n=125) dos entrevistados não sabem responder/não lembram, 31,6\% $(\mathrm{n}=83)$ afirmam que com certeza as ESF não apresentam o atributo, $14,3 \%(n=36)$ afirmam com certeza a presença do atributo nas ESF que frequentam, 4,6\% ( $n=13)$ alegam que as ESF provavelmente apresentam, enquanto $1 \%(\mathrm{n}=3)$ disse que as ESF provavelmente não apresentam.

A integralidade, os serviços disponíveis pela instituição e/ou profissional de saúde, é mensurada no componente G. Neste item, 55,67\% (n=146) dos entrevistados não sabem/não lembram, 33,07\% (n=86) relataram que com certeza as ESF não apresentam, 8,29\% $(\mathrm{n}=21)$ afirmaram que as ESF possuem com certeza a integralidade, $2 \%(\mathrm{n}=5)$ alegam que provavelmente apresentam e $1 \%(\mathrm{n}=2)$ que provavelmente não apresentam.

A integralidade que corresponde aos serviços prestados é verificada no elemento H. Quanto a isto, 51\% ( $\mathrm{n}=135)$ responderam que não sabem/não lembram, 35,69\% (n=94) relatam que não possuem com certeza, 8,29\% (n=21) alegam que possuem com certeza, $2,42 \%(n=5)$ dizem que provavelmente possuem e 2,2\% $(n=5)$ que provavelmente não possuem. 
O componente I averiguou a orientação familiar, 49,45\% ( $\mathrm{n}=133)$ relatam não saber/não lembrar, 35,42\% ( $\mathrm{n}=91$ ) negaram possuir, 8,37\% $(\mathrm{n}=21)$ dos entrevistados afirmam possuir, 4,49\% $(\mathrm{n}=10)$ alegam que provavelmente têm e $1,91 \%$ $(\mathrm{n}=5)$ provavelmente não têm.

Já o item J, que avalia a orientação comunitária, 49,74\% (n=130) dos entrevistados não sabiam/não lembravam, $39,79 \%(n=104)$ negaram apresentar, ao prazo que 6,94\% $(n=18)$ afirmam apresentar, 2,31\% $(n=5)$ dizem que provavelmente apresentam e $1,26 \%(n=3)$ que provavelmente não apresentam.

\section{Discussão}

No ano de 2015, no Brasil, o número de habitantes era 202.799.518, destes, aproximadamente 124.801 .063 (61\%) eram acompanhados pela ESF, enquanto a AB assistia em torno de 148.310.062 (73\%) indivíduos. Em 2019, a população total era 208.494.900, onde, aproximadamente, 133.261 .727 (64\%) eram observados pela ESF; cerca de 154.864 .279 (74\%) eram assistidos pela $\mathrm{AB}$ (Brasil, 2017). Nota-se que, nesses 5 anos, a cobertura aumentou, mas não exponencialmente, o que pode ter influenciado na alta taxa de ICSAP no país. Nesse período, a região estudada demonstrou uma queda nas taxas de hospitalizações evitáveis, quando comparada aos 5 anos anteriores. Além disto, no percentual total da cobertura da ESF na Região de Saúde Sudoeste I, observa-se uma baixa adesão à APS. É possível afirmar isto mediante aos resultados encontrados neste estudo, como a quantidade de AIH com diagnósticos de ICSAP, nos últimos 10 anos, e os dados que revelam que cerca de $77 \%$ da amostra da pesquisa não apresenta vínculo com a AB.

Ao serem orientados e acompanhados por uma equipe multiprofissional de saúde, os usuários da APS podem prevenir os agravos dos 19 grupos de doenças da lista. Entretanto, o estudo atual identificou que os grupos referentes às doenças respiratórias e cardiovasculares estão entre as principais causas de internações. As principais doenças relacionadas aos aspectos climáticos no mundo são: as doenças respiratórias, as cardiovasculares e a malária (Sousa, Amancio, Hacon, \& Barcellos, 2018). Todas estão na lista brasileira de ICSAP (Brasil, 2008). Portanto, estas podem ser evitadas, desde que os brasileiros tenham acesso à saúde, um direito previsto pela Constituição Federal de 1988.

Um estudo que compara as ICSAP no Brasil e em Portugal, durante o ano de 2015, demonstrou que de 11.638.853 hospitalizações no primeiro Brasil, 836.873 (7.19\%) eram evitáveis. Em contrapartida, Portugal obteve 1.000.186 internações totais, onde, aproximadamente, 100.000 eram evitáveis. A causa que apresentou a maior taxa entre ICSAP nos dois países foi a pneumonia bacteriana. No Brasil, este diagnóstico foi seguido pela infecção do trato urinário, DPOC e/ou asma. Enquanto isso, Portugal demonstrou insuficiência cardíaca congestiva e infecção do trato urinário (Rocha, Sarmento, Moita, Marques, \& Santana, 2020). Nos dados coletados na atual pesquisa, sobre as ICSAP que acometeram a população da Região de Saúde Sudoeste I nos últimos 10 anos, concordam com a pesquisa citada previamente. A única divergência é que no estudo atual o grupo de gastroenterites e suas complicações está presente entre as principais ICSAP. Essas CS na Região de Saúde abordada, podem estar associadas à cobertura deficiente da ESF, às desigualdades sociais e também às condições climáticas.

Em Goiânia - GO, entre 2008 a 2013, a taxa média de ICSAP foi de 152,7 por 10.000 habitantes, sendo os grupos de causas predominantes: gastroenterites infecciosas e complicações, infecção no rim e trato urinário, insuficiência cardíaca, doenças pulmonares e angina (Magalhães \& Morais, 2017). O município situado na Região de Saúde Central, apresentou internações por CS semelhantes a Região de Saúde Sudoeste I, isto ocorre, possivelmente devido aos aspectos climáticos do estado, às condições sanitárias, à educação em saúde da população deficiente, as comorbidades, hábitos comuns dos goianos e a cobertura insuficiente da $\mathrm{AB}$ em todo o estado.

Em diferentes pesquisas realizadas nos municípios de Florianópolis - SC, Pelotas - RS e Itaboraí - RJ (Brasil \& Juvenal, 2016; Botelho \& Portela, 2017; Costa et al., 2017), é possível evidenciar que apenas gastroenterites, pneumonia, doenças pulmonares, e insuficiência cardíaca coincidem com os achados do estudo atual. Em estudos realizados no Distrito 
Federal - DF e nos estados Rondônia -RO e Ceará - CE, identificaram ICSAP em diferentes anos (aproximadamente de 2008 a 2016), onde predominaram os diagnósticos de: angina, doenças pulmonares, asma, doenças cerebrovasculares, epilepsias, infecções de pele e do tecido subcutâneo, doenças relacionadas ao pré-natal e ao parto, entre outros. Nos 5 anos de análise de ICSAP em RO, a cobertura total da APS passou de 60,4\% em 2012 para 71,3\% em 2016 (Souza, Rehem, Santos \& Santos, 2016; Santos, Lima \& Fontes, 2019; Alves, Cavalcanti, Alves \& Costa, 2018). Desses diagnósticos, apenas as doenças pulmonares estão entre as 5 principais da pesquisa atual, seguida de angina, doenças cerebrovasculares, infecções de pele e tecido subcutâneo, e doenças relacionadas ao pré-natal e ao parto.

As pesquisas que utilizaram o instrumento PCATool versão criança em Manaus, Paraná e Paraíba, identificaram que os seguintes atributos são insatisfatórios: acesso (acessibilidade), longitudinalidade, integralidade (serviços disponíveis e prestados), orientação (familiar e comunitária). Concluíram que as unidades avaliadas não são orientadas à APS, a assistência integral à saúde da criança está ausente, o modelo focado no atendimento médico permanece, a prevenção e promoção de saúde deixam a desejar e não existem orientações individuais/comunitárias (Souza, 2016; Coutinho, Reichert, Nogueira, Toso, \& Collet, 2020). No que concerne ao grau de afiliação, em Manaus, $70 \%$ dos entrevistados possuem vínculo com a APS (Coutinho et al., 2020), diferindo do estudo atual onde $77 \%$ não possuem. Diante disto, nota-se que um município rodeado de populações ribeirinhas com enormes obstáculos à acessibilidade está altamente associado à $\mathrm{AB}$, enquanto uma região goiana em desenvolvimento não está. Isso ocorre, pois o acesso-acessibilidade deficiente possuem como barreiras: o agendamento de consultas, o acolhimento e a humanização. Na pesquisa presente, foi identificado que cerca de $85 \%$ dos pacientes negaram a presença do atributo ou alegaram não saber/não lembrar, alcançando assim, um dos piores percentuais de todos os atributos juntamente com a integralidade - serviços disponíveis (88\%) e prestados $(86 \%)$.

Tendo em consideração a avaliação da $\mathrm{AB}$ nos municípios de Diamantina-MG, Fortaleza-CE, Palmas-TO e no Sudoeste Goiano por meio das respostas de profissionais de saúde ao PCATool, denota-se que o acesso-acessibilidade é um grande desafio para APS, sendo deficiente nestes estudos. Além deste atributo, os seguintes são insatisfatórios na maioria das pesquisas: a longitudinalidade, a integralidade de serviços disponíveis e a orientação comunitária (Batista, Ribeiro, Ribeiro, Paula, \& Araújo, 2016; Rolim et al., 2019; Montelo et al., 2019; Maia et al., 2020).

Em relação ao escore geral deste estudo, o mesmo apresentou um valor baixo, sugerindo que a APS da Região abordada possui uma baixa cobertura da $\mathrm{AB}$, assim, como foi encontrado em um estudo realizado em 3 ESF de Cuiabá, cujo identificaram as seguintes médias: 2,90; 2,71 e 2,97 (Dias \& Gouveia, 2013). Em pesquisa realizada em Goiás, na Região de Saúde Sudoeste II, observou-se um escore geral elevado 7,26. Apesar das unidades serem avaliadas pelos profissionais, a média do atributo acessibilidade foi a mais baixa, 3,71 (Maia et al., 2020). Esse atributo obteve um valor abaixo do que os demais atributos avaliados também em uma pesquisa realizada no Ceará, onde se identificou a média de 2,99 (Rolim et al., 2019). As médias de Cuiabá e Ceará para esse atributo, assemelham-se ao resultado, 1,6615, encontrado pela pesquisa atual. A acessibilidade diminuída torna-se um grande problema para a Saúde Pública, uma vez que a efetivação dos princípios e das diretrizes do SUS dependem da sua porta de entrada, a AB. Sem a acessibilidade não é possível avaliar o acesso, a longitudinalidade e demais atributos.

\section{Conclusão}

Evidenciou-se que a Região de Saúde Sudoeste I possui um alto número de internações por Condições Sensíveis à APS, sendo a insuficiência cardíaca, as pneumonias bacterianas, as gastroenterites infecciosas e complicações; as infecções no rim e trato urinário e as doenças pulmonares, os grupos de causas mais prevalentes. O indicador ICSAP demonstra que as internações evitáveis na Região de Saúde Sudoeste I apesar de terem diminuído, quando comparadas aos anos anteriores, permanecem altas, se considerar que estas não deveriam ocorrer. 
Os atributos avaliados demonstraram-se baixos, destacando-se o baixo nível de vínculo entre a unidade de AB e o usuário, que demonstra que não existe acesso, tanto no âmbito de primeiro contato quanto de acessibilidade. Uma vez que o grau de afiliação é baixo, como consequência, os demais atributos são inferiores. Portanto, o acesso avaliado mostra-se inadequado. Identificando que a população da região estudada carece de orientações em saúde e as ESF não suprem a demanda, muitas vezes estão ausentes nos territórios.

Em virtude da alta taxa de ICSAP e do baixo grau de afiliação aos serviços da porta de entrada do SUS é possível afirmar que a região abordada possui uma baixa orientação à APS. Isto culmina numa baixa qualidade do acesso ao serviço prestado pela APS na Região de Saúde Sudoeste I. Diante disto, conclui-se que o acesso ao serviço prestado pela APS na região estudada encontra-se insatisfatório e necessita de adequações tais como a implantação de mais unidades com Estratégias de Saúde da Família, treinamento das equipes atuais para melhorar a humanização, conhecimento dos territórios que necessitam de cobertura e avaliação constante das unidades para evidenciar as fragilidades e saná-las.

É visível que a porta de entrada do SUS enfrenta muitos desafios e ainda não está satisfatoriamente orientada aos seus atributos. Por isso, os pesquisadores defendem a avaliação permanente do sistema, mediante a informações encontradas como neste estudo, as autoridades de saúde fomentam medidas adequadas para se obter a excelência na assistência prestada. Porque um atendimento de qualidade culmina na melhora dos indicadores de saúde.

Ressalta-se a importância de outros estudos focados na avaliação dos atributos da APS em todo país, a atuação de gestores e profissionais de saúde na remodelação de políticas públicas e em melhorias nas orientações de saúde aos usuários a fim de efetivar os princípios do SUS nas unidades.

\section{Referências}

Alves, J. W. S., Cavalcanti, C. G. C. S., Alves, R. S. M., \& Costa, P. C. (2018). Internações por Condições Sensíveis à Atenção Primária no estado do Ceará, 2010-2014. Saúde em Debate, 42, 223-235. https://doi.org/10.1590/0103-11042018s418

Barbiani, R., Junges, J. R., Nora, C. R. D., \& Asquidamini, F. (2014). A produção científica sobre acesso no âmbito do Sistema Único de Saúde do Brasil: avanços, limites e desafios. Saude soc., 23(3), 855-868. https://doi.org/10.1590/S0104-12902014000300010

Batista, V. C. L., Ribeiro, L. C. C., Ribeiro, C. D. A. L., Paula, F. A., \& Araújo, A. (2016). Avaliação dos atributos da Atenção Primária à Saúde segundos os profissionais de saúde da família. SANARE, 15(2), 87-93. https://sanare.emnuvens.com.br/sanare/article/view/1042

Botelho, J. F., \& Portela, M. C. (2017). Risco de interpretação falaciosa das internações por condições sensíveis à atenção primária em contextos locais, Itaboraí, Rio de Janeiro, Brasil, 2006-2011. Cad. Saúde Pública, 33(3). https://doi.org/10.1590/0102-311x00050915

Brasil. (2003). Para entender a gestão do SUS. Brasília: Ministério da Saúde. https://bvsms.saude.gov.br/bvs/publicacoes/para_entender_gestao.pdf

Brasil. (2007). Assistência de Média e Alta Complexidade no SUS. Brasília: CONASS. https://bvsms.saude.gov.br/bvs/p ublicacoes/colec_progestores_livro9.pdf

Brasil. (2010). Manual do instrumento de avaliação da atenção primária à saúde: primary care assessment tool pcatool - Brasil. Brasília: Ministério da Saúde. http://bvsms.saude.gov.br/bvs/publicacoes/manual_avaliacao_pcatool_brasil.pdf

Brasil. (2017). Art. 198. Senado Federal. https://www.senado.leg.br/atividade/const/con1988/con1988_06.06.2017/art_198_.asp

Brasil. (2017). Egestor: Cobertura da Atenção Básica. Ministério da Saúde. https://egestorab.saude.gov.br/paginas/acessoPublico/relatorios/ relHistoricoCobertu raAB.xhtml

Brasil. (2020). Regionais de Saúde do Estado de Goiás. Ministério da Saúde. https://www.saude.go.gov.br/unidades-de-saude/regioes-de-saude

Brasil. Portaria n 221 de 17 de abril de 2008. (2008). Saúde Legis. https://bvsms.saude.gov.br/bvs/saudelegis/sas/2008/prt0221_17_04_2008.html

Brasil. Portaria n. 930 de 15 de maio de 2019. (2019). Diário Oficial da União, 94, 122. https://www.in.gov.br/web/dou/-/portaria-n\%C2\%BA-930-de-15-demaio-de-2019-104562211

Brasil. Portaria n. 2.436 de 21 de setembro de 2017. (2017). Portal da Legislação. http://bvsms.saude.gov.br/bvs/saudelegis/gm/2017/ prt2436_22_09_2017.html

Brasil, V. P. C., \& Juvenal, S. D. (2016). Hospitalizações por condições sensíveis à atenção primária em Florianópolis, Santa Catarina - estudo ecológico de 2001 a 2011. Epidemiologia e Serviços de Saúde, 25(1), 75-84. https://doi.org/10.5123/s1679-49742016000100008 
Campos, R. T. O., Ferrer, A. L., Gama, C. A. P., Campos, G. W. S, Trapé, T. L., \& Dantas, D. V. (2014). Avaliação da qualidade do acesso na atenção primária de uma grande cidade brasileira na perspectiva dos usuários. Saúde debate, 38, 252-264. https://doi.org/10.5935/0103-1104.2014S019

Campos, G. W. S. (2015). Paradoxos na construção do SUS. Physis, 25(3),705-8. https://doi.org/10.1590/S0103-73312015000300002

Carriello, L. S. S., Souza, A. C., \& Vallegas, A. B. (2020). Estratégia Saúde da Família e sua interferência nas internações sensíveis à atenção primária à saúde. Research, Society and Development, 9(7). https://doi.org/10.33448/rsd-v9i7.5017

Costa, J. S. D., Teixeira, A. M. F. B., Moraes, M., Strauch, E. S., Silveira, D. S., Carret, M. L.V., \& Fantinel, E. (2017). Hospitalizações por condições sensíveis à atenção primária em Pelotas: 1998 a 2012. Rev. bras. epidemiol, 20(2), 345-354. http://dx.doi.org/10.1590/1980-5497201700020014.

Coutinho, S. E. D., Reichert, A. P. S., Nogueira, J. A., Toso, B. R. G. O., \& Collet, N. (2020). Avaliação em saúde: dimensão processual e estrutural da saúde da criança na atenção primária. Saúde em Debate, 44(124), 115-129. https://doi.org/10.1590/0103-1104202012408

Dias, K. A. P. L., \& Gouveia, G. C. (2013). Assistência em saúde: uma visão dos usuários e profissionais da atenção básica - Cuiabá - MT. Tese de Mestrado[dissertação]. Fundação Oswaldo Cruz, Recife, PE, Brasil. https://www.arca.fiocruz.br/handle/icict/31920

Gadelha, P. (2015). Conferência Nacional de Saúde: desafios para o país. Cad. Saúde Pública, 31(10), 2047-2058. https://doi.org/10.1590/0102$311 \mathrm{XDE} 011015$

Instituto Brasileiro de Geografia e Estatística. (2019). Panorama de Rio Verde-GO. https://cidades.ibge.gov.br/brasil/go/rioverde/pesquisa/23/25207?tipo=ranking

Lima, S. A. V., Silva, M. R. F., Carvalho, E. M. F., Pessoa, E. A. C., Brito, E. S. V., \& Braga, J. P. R. (2015). Elementos que influenciam o acesso à atenção primária na perspectiva dos profissionais e dos usuários de uma rede de serviços de saúde do Recife. Physis, 25(2), 635-656. http://dx.doi.org/10.1590/S010373312015000200016

Magalhães, A. L. A., \& Morais, N. O. L. (2017). Desigualdades intraurbanas de taxas de internações por condições sensíveis à atenção primária na região central do Brasil. Ciênc. saúde coletiva, 22(6), 2049-2062. https://doi.org/10.1590/1413-81232017226.16632016

Maia, L. G., Silva, L. A., Guimarães, R. A., Pelazza, B. B., Leite, G. R., \& Barbosa, M. A. (2020). A qualidade de serviços de atenção primária, a formação profissional e o Programa Mais Médicos em uma região de saúde do sudoeste goiano. Rev. bras. epidemiol, 23. https://doi.org/10.1590/1980-549720200014

Montelo, F. M., Monturil, L. A., Moura, E. F., Barasuol, A. M., Dodero, S. R., Maciel, E. S., \& Quaresma, F. R. P. (2019). Avaliação dos Atributos da Atenção Primária à Saúde: Visão dos Profissionais. Enferm. Foco, 10(6), 111-117. https://doi.org/10.21675/2357-707X.2019.v10.n6.2778

Oliveira, M. A. C., \& Pereira, I. C. (2013). Atributos essenciais da Atenção Primária e a Estratégia Saúde da Família. Rev. bras. enferm, 66, 158-164. https://doi.org/10.1590/S0034-71672013000700020

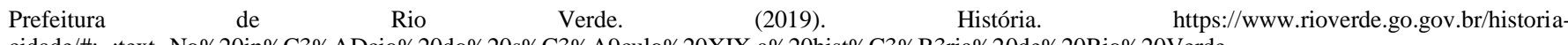
cidade/\#: :text=No\%20in\%C3\%ADcio\%20do\%20s\%C3\%A9culo\%20XIX,a\%20hist\%C3\%B3ria\%20de\%20Rio\%20Verde

Rocha, J. V. M., Sarmento, J., Moita, B., Marques, A. P., \& Santana, R. (2020). Comparative research aspects on hospitalizations for ambulatory care sensitive conditions: the case of Brazil and Portugal. Ciênc. saúde coletiva, 25(4), 1375-1388. http://dx.doi.org/10.1590/1413-81232020254.13502019.

Rolim, L. B., Monteiro, J. G., Meyer, A. P. G. F. V., Nuto, S. A. S., Araújo, M. F. M., \& Freitas, R. W. J. F. (2019). Avaliação dos atributos da Atenção Primária à Saúde de Fortaleza, Ceará, Brasil. Rev. Bras. Enferm., 72(1), 1926. https://doi.org/10.1590/0034-7167-2018-0033

Santos, B. V., Lima, D. S. F., \& Fontes, C. J. F. (2019). Internações por condições sensíveis à atenção primária no estado de Rondônia: estudo descritivo do período 2012-2016. Epidemiologia e Serviços de Saúde. 28(1). https://doi.org/10.5123/s1679-49742019000100001

Santos, L. R. C. S., \& Silva, T. P. C. (2013). A utopia da Reforma Sanitária Brasileira em um discurso no Congresso da ABRASCO 2009. Saúde debate, 37(97), 210-218. https://www.scielo.br/scielo.php?script=sci_arttext\&pid=S0103-11042013000200003\&lng=en\&nrm=iso

Silva, S. A., Nogueira, D. A., Paraizo, C. M. S., \& Fracolli, L. A. (2014). Avaliação da Atenção Primária à Saúde: visão dos profissionais de saúde. Rev. esc. enferm. USP, 48, 122-128. https://doi.org/10.1590/S0080-623420140000600018

Sousa, N. P., Rehem, T. C. M. S. B., Santos, W. S., \& Santos, C. E. (2016). Internações sensíveis à atenção primária à saúde em hospital regional do Distrito Federal. Rev. Bras. Enferm., 69(1), 118-125. https://doi.org/10.1590/0034-7167.2016690116i

Sousa, T. C. M., Amancio, F., Hacon, S. S., \& Barcellos, C. (2018). Doenças sensíveis ao clima no Brasil e no mundo: revisão sistemática. Rev. Panam. Salud Públ., 42(85). https://doi.org/10.26633/RPSP.2018.85

Souza, L. E. P. F., Paim, J. S., Teixeira, C. F., Bahia, L., Guimarães, R., Almeida Filho, N., Machado, C. V., Campos, G. W., \& Azevedo e Silva, G. (2019). Os desafios atuais da luta pelo direito universal à saúde no Brasil. Ciênc. saúde coletiva, 24(8), 2783-2792. https://doi.org/10.1590/141381232018248.34462018

Souza, S. S. (2016). Avaliação dos atributos essenciais da Atenção Básica em Saúde da Criança: Estudo de Caso no Distrito de Saúde Norte da cidade de Manaus-AM. Tese de Mestrado. Universidade Federal do Amazonas, Manaus, AM, Brasil. https://www.arca.fiocruz.br/handle/icict/31081

Starfield, B. (2002). Atenção primária: equilíbrio entre necessidades de saúde, serviços e tecnologia. Brasília: UNESCO, Ministério da Saúde. https://www.nescon.medicina.ufmg.br/biblioteca/imagem/0253.pdf 